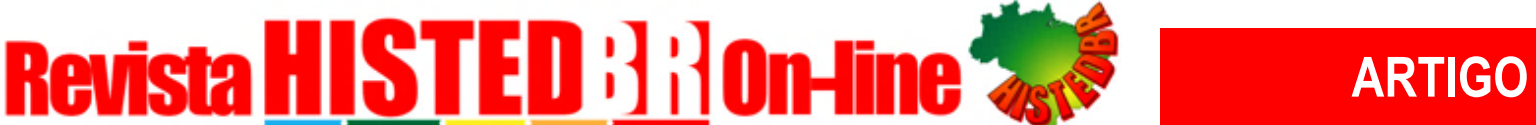

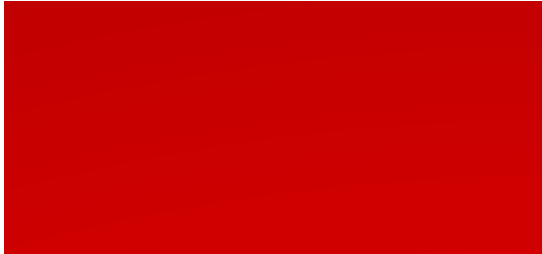

A Revista HISTEDBR On-line publica artigos resultantes de estudos e pesquisas científicas que abordam a educação como fenômeno social em sua vinculação com a reflexão histórica

Correspondência ao Autor Nome: Iara Augusta da Silva E-mail: iara2ufms@gmail.com Instituição: Universidade Estadual de Mato Grosso do Sul, Brasil

Submetido: 02/08/2020

Aprovado: 23/03/2021

Publicado: 02/08/2021

doi> 10.20396/rho.v21i00.8660735 e-Location: e021042 ISSN: 1676-2584

Como citar ABNT (NBR 6023):

SILVA, I. A. da; RUBINHO, V. da

S.; CARDOSO, P. F. da S. Os

textos escolares na Didáctica

Magna de Coménio. Revista

HISTEDBR On-line, Campinas,

SP, v. 21, p. 1-21, 2021. DOI:

10.20396/rho.v21i00.8660735.

Disponível em:

https://periodicos.sbu.unicamp.br/o js/index.php/histedbr/article/view/8 660735. Acesso em: 02 ago. 2021

\section{OS TEXTOS ESCOLARES NA DIDÁCTICA MAGNA DE COMÉNIO}

\section{(9attes Iara Augusta da Silva*}

Universidade Estadual de Mato Grosso do Sul

\section{(9) Lattes Vanessa da Silva Rubinho**}

Secretaria de Estado de Educação de Mato Grosso do Sul

(9) Lattes Patricia Florencio da Silva Cardoso****

Escola Municipal Prof. Licurgo de Oliveira Bastos

\section{RESUMO}

Este artigo tem como finalidade analisar a concepção e a função dos textos escolares propostos por João Amós Coménio (15921670), na Didáctica magna escrita nos meados do século XVII. Realizou-se o mapeamento de uma obra clássica da pedagogia para destacar a questão dos manuais didáticos no âmbito da organização do trabalho didático, tendo em vista a sua contextualização histórica na passagem da idade média para a sociedade moderna com o surgimento das manufaturas, forma inicial do modo de produção capitalista (meados do século XVI ao último terço do século XVIII), fundada na divisão do trabalho. Para fundamentar teoricamente as análises e reflexões, numa abordagem histórica, priorizou-se as produções acadêmicas de Alves (2001, 2005, 2011, 2015), de Centeno (2009), de Brito (2010) e de Souza (2010). O estudo revelou o caráter central desse instrumento de trabalho do professor, na organização da escola moderna pensada por Coménio para oferecer educação para todos. Tendo consciência das limitações materiais de sua época para colocar em prática o seu projeto de universalização da educação, o pensador morávio, propôs a utilização dos textos escolares para o professor e para os alunos, em todos os graus da instituição escolar pública, naquele momento histórico.

PALAVRAS-CHAVE: Textos escolares comenianos. Organização do trabalho didático. Escola pública moderna.

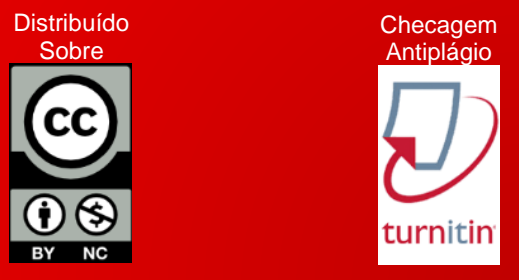




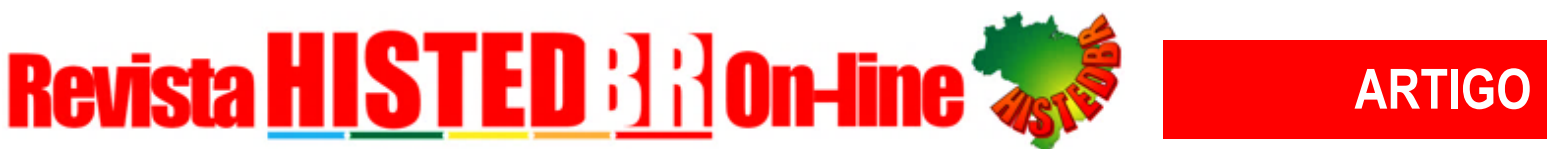

SCHOOL TEXTS IN THE COMENIU'S DIDACTICA MAGNA

\begin{abstract}
This article analyzes and interprets the function of the school texts proposed by João Amós Comênio (1592-1670), in the Didactics written in the middle of the 17th century. It was done a mapping a classic work of pedagogy to address the question of textbooks within the scope of the organization of didactic work, having in mind the historical context in the transition from the middle ages to a modern society with the emergence of manufactures, the initial form of capitalist production (mid16 th century to the last third of the 18th century), founded on the division of labor. Justifying the theoretical basis and reflections, in a historical perspective, it was prioritized as academic productions by Alves (2001, 2005, 2011, 2015), Centeno (2009), Brito (2010) and Souza (2010). The study revealed the central character of this instrument of work of the teacher in the organization of the modern public school designed by Comênio to offer education for all. Aware of the material limitation of his time to put into practice or execute the project of universal education, the Moravian thinker proposed the use of school texts for teachers and students, in all grades of public school, at the historical moment.
\end{abstract}

Keywords: Comenian school texts. Organization of didactic work. Modern public school.

\section{LOS TEXTOS DE LA ESCUELA EN LA DIDÁCTICA MAGNA DE COMÉNIO}

\begin{abstract}
Resumen
Este artículo tiene como objetivo analizar la concepción y función de los textos escolares propuestos por Joao Amos Comnio (1592-1670), en didáctica magna escritos a mediados del siglo XVII. Se llevó a cabo una obra clásica de pedagogía para abordar la cuestión de los manuales didácticos en el contexto de la organización del trabajo didáctico, en vista de su contextualización histórica en el paso de la Edad Media a la sociedad moderna con el surgimiento de las manufacturas, una forma inicial de modo de producción capitalista (de mediados del siglo XVI al último tercio del siglo XVIII), fundada en la división del trabajo. Para basar teóricamente los análisis y reflexiones, desde una perspectiva histórica, se priorizaron las producciones académicas de Alves $(2001,2005,2011,2015)$, Centeno (2009), Brito (2010) y Souza (2010). El estudio reveló el carácter central de este instrumento de trabajo del maestro en la organización de la escuela pública moderna diseñada por Coménio para ofrecer educación para todos. Consciente de las limitaciones materiales de su tiempo para poner en práctica su proyecto de universalización de la educación, el pensador Morávio propuso el uso de textos escolares para el maestro y para los estudiantes, en todos los grados de la institución de la escuela pública, en ese momento histórico.
\end{abstract}

Palabras clave: Libros de texto de Comenian. Organización del trabajo didáctico. Escuela pública moderna. 


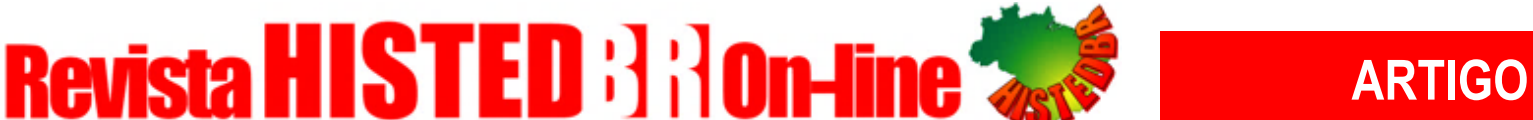

\section{INTRODUÇÃO}

O objetivo deste trabalho é estudar a concepção e a função dos textos escolares na obra de João Amós Coménio (1592-1670). Para o desenvolvimento da pesquisa procedeuse a releitura da Didáctica magna, escrita por Coménio em 1657, destacando-se, ao longo dos XXXIII capítulos que compõem a obra, as considerações do autor a respeito da utilização do texto escolar no âmbito da organização do trabalho didático. Ao tratar de seu método de "ensinar tudo a todos", com riqueza de detalhes, Coménio deixa claro ao leitor o papel e o significado desse instrumento de trabalho do professor.

O mapeamento da obra permite dizer, com segurança, que o manual didático ${ }^{1}$ é uma tecnologia que ocupa posição central na organização da instituição escolar proposta pelo educador morávio, nos meados do século XVII. Para ele, o conhecimento a ser ministrado pelo professor deveria estar compilado nos livros de texto, de forma a tornar o processo educativo mais breve, mais fácil e mais sólido. Coménio (1996, p. 469), ao referir-se aos requisitos para colocar em prática sua proposta educacional, afirma, categoricamente, ser de extraordinária importância uma provisão suficiente de “[...] livros pan-metódicos.” Uma vez, tendo disponível o material impresso, não é difícil encontrar quem possa, saiba e queira utilizá-lo e, também, quem possa comprá-lo a preço acessível.

Os estudos desenvolvidos pelos pesquisadores integrantes do Grupo de Trabalho do HISTEDBR, unidade regional de Mato Grosso do Sul, têm contribuído para elucidar a função do manual didático no âmbito da relação educativa. O pressuposto básico dos estudos é compreender esse instrumento do trabalho didático no movimento mais amplo da produção capitalista e do trabalho em seu sentido mais geral. Dessa forma, o manual didático, colocado no leito da história, tem sido analisado, considerando o seu papel no âmbito da organização do trabalho didático ${ }^{2}$ da escola moderna, pensada, inicialmente, por Coménio, na Didáctica magna. Com esse propósito, esse coletivo de pesquisadores ligados ao HISTEDBR/MS ${ }^{3}$ tem produzido um conjunto significativo de artigos no sentido de tornar público os estudos que vem desenvolvendo já há algum tempo. Assim, por exemplo, na Revista HISTEDBR Online, número especial, de maio de 2010 encontra-se uma coletânea de artigos que versam sobre a organização do trabalho didático e o manual didático na referida abordagem teóricometodológica.

Diante do exposto, o que se propõe, neste trabalho, é realizar um estudo da concepção e da função dos textos escolares propostos por Coménio, na Didáctica magna.

\section{COMÉNIO E A DIDÁTICA MAGNA: ALGUMAS CONSIDERAÇÕES GERAIS}

A educação moderna nasceu no interior do movimento de transformação da sociedade feudal. A Didáctica magna, um texto clássico da pedagogia, é um marco nesse 


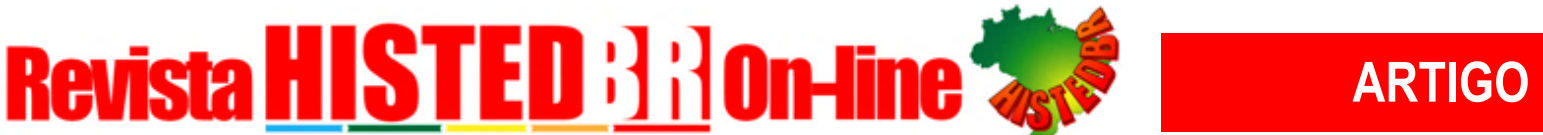

processo. A obra contém a linha fundamental do modelo de educação apregoado por Coménio, cujo pensamento está na origem da organização educacional burguesa.

Os estudos desenvolvidos por Alves (2001) têm demonstrado que, para entender a gênese da escola moderna, é necessário se reportar aos escritos de Coménio, visto que foi este pensador quem lançou as suas bases. O educador morávio teria sido o primeiro a elaborar, de forma sistemática, uma didática na perspectiva moderna ${ }^{4}$.

Alves (2001), ao abordar a origem social da escola pública contemporânea, parte de uma tese central: a chave que explica a origem da educação moderna é o trabalho. É na materialidade das relações capitalistas do trabalho que o historiador da educação vai fixar sua análise. Para ele, também, o trabalho didático vai, como toda e qualquer forma de trabalho gerada sob a ótica burguesa, sofrer as determinações da divisão do trabalho. Para radicalizar, afirma ser manufatureira a escola do nosso tempo e localiza na época das manufaturas a origem desta instituição. A mesma divisão manufatureira do trabalho, imposta ao modo de produção capitalista, acabará por determinar a organização da escola moderna.

Na introdução da Didáctica magna, Coménio (1996, p. 45) promete apresentar um "[...] método universal de ensinar tudo a todos." Ou seja, um método que permita toda a "[...] juventude de ambos os sexos [...]" (COMÉNIO, 1996, p. 139) aprender de maneira rápida, sólida e segura.

Nós ousamos prometer uma Didáctica Magna, isto é, um método universal de ensinar tudo a todos. E de ensinar com tal certeza, que seja impossível não conseguir bons resultados. E de ensinar ràpidamente, ou seja, sem nenhum enfado e sem nenhum aborrecimento para os alunos e para os professores, mas antes com sumo prazer para uns e para outros. E de ensinar sòlidamente, não superficialmente e apenas com palavras, mas encaminhando os alunos para uma verdadeira instrução, para os bons costumes e para a piedade sincera. (COMÉNIO, 1996, p. 45-46, grifo do autor).

A preocupação do autor em dar uma organização ao trabalho didático, de modo que ele se torne mais rápido e seguro, emerge da própria produção material. O modo de produção das corporações medievais dava sinais de declínio. As corporações, baseadas no trabalho artesanal, passaram a sofrer concorrência direta das manufaturas capitalistas, apoiadas na utilização do princípio da divisão do trabalho. O novo modo de produção capitalista impunha profundas alterações no processo de trabalho vigente à época. Os operários assalariados, reunidos num único local e sob o comando do capitalista, passam a trabalhar juntos, de acordo com um plano de produção, constituindo o que Marx (1989) chamou, em O capital, de regime de cooperação e, posteriormente, de manufaturas. Essa nova forma de organizar o trabalho, fundada na divisão de tarefas, está refletida na organização do trabalho didático pensada por Coménio.

A construção da proposta de Coménio tem, portanto, como princípio, a divisão do trabalho (etapas de ensino, séries, áreas de conhecimentos). Essa divisão se configura na organização da atividade docente, que ele resume com a palavra "método". Tudo poderia ser 


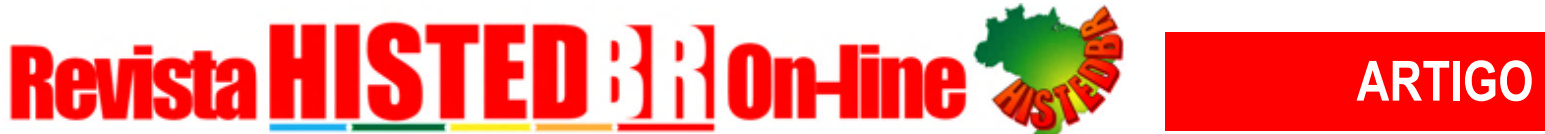

ensinado e aprendido com rapidez e facilidade, desde que a disposição do ensino obedecesse ao método. Em Coménio, método consiste numa disposição racional e sistemática dos procedimentos pedagógicos de tal modo que, seguindo-os, qualquer professor, com instrumentação adequada, poderia transmitir um determinado conteúdo. Isto indica claramente uma preocupação do autor com a simplificação do trabalho do professor.

A ênfase na "arte de ensinar" mudou o enfoque educacional. Todo conhecimento a ser transmitido deveria, conforme Coménio, estar garantido, não na formação do educador, como ocorria na idade média, em que só poderia oferecer trabalho como preceptor quem detivesse os mais elevados conhecimentos, mas na "arte", entendida como um conjunto de regras. Todos os professores, independente, da sua formação, deveriam transmitir conhecimento a seus alunos desde que obedecessem a determinados procedimentos didáticos e usassem recursos, como, por exemplo, o manual didático. Coménio, ao apresentar uma proposta pedagógica baseada em procedimentos e recursos que dispensam a erudição do preceptor, cria condições para o estabelecimento de ensino na sua forma moderna.

É preciso constituir uma "arte" do ensino, tendo como principal instrumento de trabalho o manual didático. É por meio dela que se deve garantir a transmissão do conhecimento. Antes, na forma social anterior, não havia didática no sentido que Coménio confere ao termo. $\mathrm{O}$ trabalho de ensinar alguém era regulado pela vontade de quem assumia o papel de professor. A rigor, a figura do professor, como profissional da educação, não existia. Existia, isto sim, o preceptor. Preceptor e professor parecem ser, nesse sentido, personagens sociais distintos. A emergência de um novo profissional é uma imposição das necessidades implicadas no processo da universalização do saber. Para se educar um número cada vez maior de crianças e de jovens, agora reunidos em classes, é que surge a figura do professor. O trabalho desse novo personagem social foi organizado em bases distintas daquelas em que estava assentado o trabalho pedagógico medieval. Ao invés da assistência individual, própria ao preceptor medieval, sucedeu a assistência coletiva, própria de quem tem que ensinar tudo a todos, simultaneamente.

Na sua estrutura, a Didáctica magna revela a filosofia da educação e a concepção de ensino propostas pelo seu autor. Ao abordar a questão com a qual se ocupa o pensador, partindo dos princípios gerais, desce aos intermediários e específicos para, finalmente, tratar a respeito da prática escolar. $\mathrm{Na}$ exposição do tema, um elemento serve de critério de organização do texto - a oposição à escolástica feudal - forma vigente da educação à época.

A disposição do pensador morávio é dar ao ensino uma nova configuração. Para ele, isso só seria possível mediante o combate ao velho edifício que estruturava a educação de seu tempo ${ }^{5}$. Ele afirma ser preciso, para edificar o novo, demolir o velho. É nesse tom que, saudando os leitores, Coménio (1996, p. 49) inaugura o texto: "Com efeito, quem projecta construir um novo edifício começa habitualmente por aplanar o terreno, indo até a demolição do velho edifício, pouco cómodo e a ameaçar ruína." 


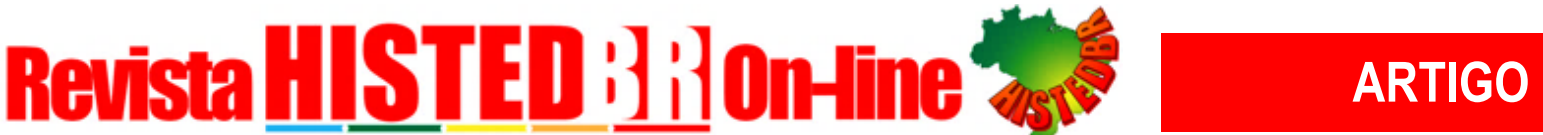

$\mathrm{Na}$ exposição dos fins da educação, o caráter de oposição, ainda que velado, do pensamento comeniano em relação àquilo em que a escolástica, base da educação medieval, havia se transformado, aparece delineado. É o que deixa transparecer o modo como este autor entende o homem e a educação. À concepção medieval que conferia exclusivamente a Deus o atributo da excelência, Coménio (1996, p. 81-82) opõe uma concepção de homem que valoriza as potencialidades e capacidades humanas, a ponto de supô-las capazes de tornar o homem digno de desfrutar, como o próprio Deus, da perfeição. Para Coménio, o destino humano é uma responsabilidade, também, do próprio homem. $\mathrm{O}$ homem é concebido como um ser sublime e perfeito, dotado de possibilidades que o permitem adquirir sabedoria mais elevada e, com ela, alcançar o patamar que lhe aprouver.

Outro aspecto presente na obra e que está associado à origem da pedagogia moderna, é o conceito de "universalização da educação". Na Didáctica magna, o fio condutor é a universalização do conhecimento. Como representante da Reforma Protestante, Coménio pleiteava o direito de todos de aprender ler e escrever, como uma forma de acesso aos ensinamentos da Sagrada Escritura. A defesa da universalização é marcada por uma expressão sistematicamente repetida na obra: Ensinar tudo a todos. O educador (1996, p. 139) diz que, "[...] devem ser enviados às escolas não apenas os filhos dos ricos ou dos cidadãos principais, mas todos por igual, nobres e plebeus, ricos e pobres, rapazes e raparigas, em todas as cidades, aldeias e casais isolados."

Para o pensador (1996, p. 46-47), a função da educação excede o papel formativo, no sentido mais estreito do termo. A ela compete, também, o papel de redentora da própria humanidade. Em diversas passagens da Didáctica magna, Coménio reitera sua crença no poder da educação. Educação, para ele, é mais que um instrumento de constituição da humanidade no homem; ela redime o gênero humano.

Após a apresentação dos princípios teológico-filosóficos da educação, onde frisa que o homem contém em si os germes do conhecimento das coisas que o cercam, Coménio expõe, com detalhes, os fundamentos do seu método ou da sua didática, pensada com a finalidade de promover experiências que possam favorecer o papel da educação enquanto fator de desenvolvimento das potencialidades humanas. Coménio depositava grande poder ao método. Tudo poderia ser ensinado e aprendido com sucesso absoluto, desde que fosse utilizado o método correto. Da mesma forma que, para plantar uma árvore, pintar um quadro ou construir um edifício, é necessária certa arte e certa habilidade, também, para imprimir conhecimento na mente dos jovens é preciso que o professor conheça a arte de educar. A arte de ensinar se constitui, de maneira geral, de um conjunto de regras e procedimentos relacionados basicamente ao trabalho do professor e à ação do aluno. É, justamente, para mediar a relação educativa, que Coménio concebeu o manual didático, instrumento central na organização do trabalho didático proposto pelo educador morávio. De acordo com os estudos de Alves (2011, p. 4-5):

Comenius fundou-a [relação educativa] no instrumento de trabalho e, além de celebrar o manual didático como a garantia da transmissão do 


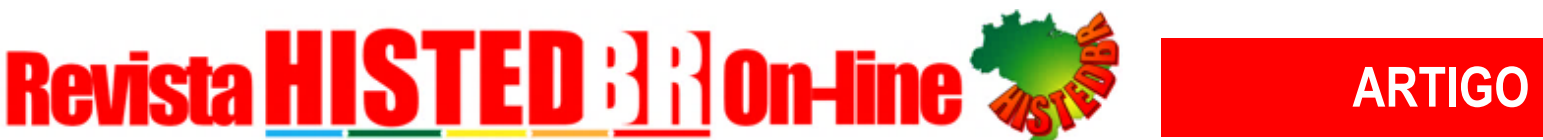

conhecimento, conferiu-lhe uma função excludente. Ao reconhecer que ele bastava ao trabalho didático, fixou o seu caráter especializado e tornou possível banir de dentro da sala de aula todas as outras modalidades de livros. Ao emprestar tom categórico à regra "não dar aos alunos nenhuns livros, além dos da sua classe" (COMÉNIO, 1976, p. 226), estabeleceu o império do manual didático.

Feitas estas considerações gerais, necessárias, pois permitem a compreensão do momento histórico no qual Coménio produziu a Didáctica magna, bem como os fundamentos dessa obra, será exposto a seguir, o que diz o pensador, especificamente, a respeito dos textos escolares.

\section{REQUISITOS PARA ENSINAR E PARA APRENDER COM SEGURANÇA, COM FACILIDADE, COM SOLIDEZ E COM RAPIDEZ: O USO DOS TEXTOS ESCOLARES}

A exposição dos fundamentos do método para ensinar e aprender ocupa cinco capítulos da Didáctica magna, indo do XV ao XIX ${ }^{6}$. Coménio, ao propor o método universal de ensinar tudo a todos, não se restringe a explicitar o seu funcionamento, mas procura expor também os fundamentos que lhe dão sustentação, a partir da crítica incisiva que realiza à didática reinante nas escolas de seu tempo. A natureza constitui o modelo basilar de todas as artes, inclusive, o da arte de ensinar. Obedecendo às leis da natureza, aliás, como fazem os artesãos, é certo o professor obter êxito na arte de ensinar. Por não imitarem esse modelo oferecido pela natureza e pelos artesãos, as escolas da época apresentavam verdadeiras "aberrações" que deveriam ser corrigidas. Essas correções constituem-se em normas e procedimentos orientadores do trabalho do professor e das atividades dos alunos. (COMÉNIO, 1996, p. 187-190).

Ao discorrer a respeito dos procedimentos a serem adotados pelo professor, para conduzir o processo de ensino, Coménio vai explicitando a sua concepção e a função que ele atribui aos textos escolares. De início, o pensador morávio faz duas recomendações acerca destes instrumentos didáticos: "I. Não dar aos alunos nenhuns outros livros, além dos da sua classe; II. Que esses livros sejam tão cuidadosamente ilustrados que, justa e merecidamente, possam ser considerados verdadeiros inspiradores de sabedoria, de moralidade e de piedade." (COMÉNIO, 1996, p. 226).

O pensador é bastante incisivo ao afirmar que uma das causas do atraso das escolas do seu tempo era a permissão que os mestres davam aos alunos de ter acesso a outros livros, além dos chamados "livros de texto" a ser utilizado em cada classe. Com o uso de diversos livros, somente as inteligências mais dotadas seriam capazes de se desvencilhar dos labirintos dos vários campos do conhecimento. Então, Coménio (1996, p. 288) assevera: "[...] Efectivamente, quanto menos os outros livros ocuparem os olhos, tanto mais os livros 


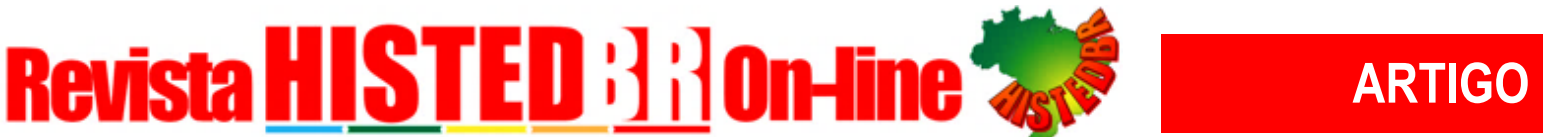

de texto ocuparão a mente." Ao reduzir a pluralidade dos livros, o professor estaria instruindo os alunos segundo o princípio de "economia de tempo e fadiga".

Os livros de texto, conforme o educador morávio para atender às leis da facilidade, da solidez e da brevidade, deveriam expor as coisas de "modo familiar e popular", pois, assim, tornaria tudo o que é necessário aprender, acessível a todos os estudantes, mesmo sem a presença do professor. Desta forma, para ele, o manual didático era um instrumento fundamental na organização do trabalho escolar, uma vez que ele poderia substituir até a figura do professor. Coménio expressa, o que se está dizendo, com as seguintes palavras:

Estes livros, portanto, deverão ser conformes às nossas leis da facilidade, da solidez e da brevidade, e contar, para todas as escolas, tudo o que é necessário, de modo completo, sólido e aprimorado, para que sejam uma imagem verdadeira de todo o universo (o qual deve ser impresso nas mentes juvenis). E (o que vivamente desejo e inculco) que esses livros exponham todas as coisas de modo familiar e popular, para que tornem tudo acessível aos alunos, de modo que o entendam por si, mesmo sem qualquer professor. (COMÉNIO, 1996, p. 289).

Para que a instrução da juventude fosse sólida, era essencial que os livros a serem utilizados nas escolas fossem produzidos a partir de um "luminoso exemplo da natureza", qual seja, ensinar as coisas de forma distinta. Assim, para facilitar tanto a quem ensinava quanto a quem aprendia, os livros deveriam ser elaborados com a preocupação de apresentar os conteúdos de maneira o mais distintamente possível, de forma a evitar confusão. (COMÉNIO, 1996, p. 260). Além disso, os livros, para ensinar com vantajosa rapidez, deveriam expor as coisas resumidamente. Por exemplo, para ensinar as artes e as línguas, Coménio (1996, p. 294) afirma ser necessário escolher ou fazer novos livros de "[...] pequeno tamanho e de notável utilidade, que exponham as coisas sumàriamente, ou seja, muitas coisas em poucas palavras."

\section{O ENSINO DAS LÍNGUAS E OS TEXTOS ESCOLARES}

Uma parte da Didáctica magna é consagrada às observações feitas a aspectos específicos do conhecimento humano. $\mathrm{O}$ autor propõe um conjunto de informações, de procedimentos, de conselhos no que se refere ao modo de ensinar "metodicamente" (de modo fácil, sólido e rápido) as ciências, as artes, as línguas, a moral e a piedade (religião). A leitura do texto nos permite entender como o professor deve proceder para que os alunos aprendam as coisas relacionadas com o seu cotidiano, os instrumentos e as formas de trabalho, as línguas que permitem a comunicação entre os povos, os princípios da virtude e, sobretudo o sentimento de respeito às coisas da religião.

Ao abordar, em particular, o método para ensinar as línguas, Coménio trata com detalhe a questão dos manuais didáticos. Dando prioridade ao ensino da língua vernácula sobre as demais (o grego, o latim, o hebraico), o educador morávio explicita, inicialmente,

\begin{tabular}{l|l|l|l|l|l} 
(C) Rev. HISTEDBR On-line & Campinas, SP & v.21 & $1-21$ & $\mathrm{e} 021042$ & 2021 \\
\hline
\end{tabular}




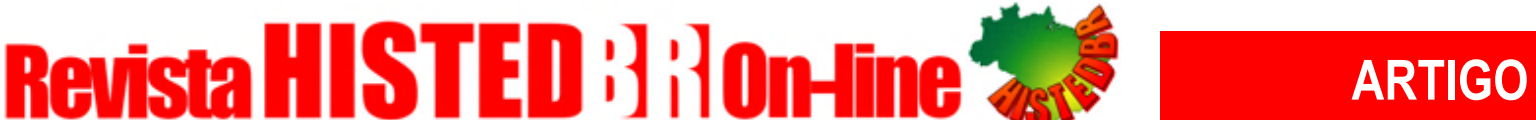

que as crianças devem aprender as palavras paralelemente com as coisas para que elas possam apreender o sentido e a função dos vocábulos. Tendo em vista este pressuposto, Coménio (1996, p. 332) esclarece que escreveu um livro denominado a Porta das línguas, "[...] onde as palavras que formam as frases exprimem ao mesmo tempo a estrutura das coisas, e (ao que parece) com bons resultados."

Os estudantes são conduzidos com maior facilidade e rapidez no processo de conhecimento das línguas, quando se considera os graus que correspondem às suas idades. Além disso, Coménio (1996, p. 337) acrescenta que o ensino das línguas será exitoso se tanto os "[...] livros didácticos, para serem postos nas mãos dos alunos, como os livros informativos, compilados para uso dos professores, são, uns e outros, breves e metódicos." Neste trecho, é possível perceber com clareza a natureza dos manuais didáticos concebidos por Coménio, no século XVII: brevidade e sistematização dos conhecimentos a serem veiculados pela escola.

Para ensinar a língua, Coménio indica quatro tipos de livros didácticos para serem utilizados pelos alunos. Os conteúdos desses livros estão organizados de modo a atender o curso do desenvolvimento das crianças e dos jovens.

20. O Vestíbulo deve conter matéria para balbuciantes, algumas centenas de vocábulos ligados em forma de pequenas frases, tendo anexas as tábuas das declinações e das conjugações. 21. A Porta deve conter todas as palavras mais usadas da língua, cerca de oito mil, reunidas sob a forma de pequenas frases, que exprimam ao vivo as coisas, na sua situação natural. (...). 22. O Palácio deve conter vários trechos acerca de todas as coisas, cheios de todo género de frases e de flores de elegância, com notas marginais que indiquem de que autor foi tirado cada um dos escritos. (...). 23. Dá-se o nome de Tesoiro aos autores clássicos que escreveram, com gravidade e vigor, acerca de qualquer assunto. (COMÉNIO,1996, p. 338339).

Observa-se no excerto que cada um dos livros traz as indicações necessárias para conduzir a aprendizagem de uma língua, seguindo uma progressão de complexidade para atender a fase de vida do ser humano. No livro, o Tesoiro, a ser usado pelos alunos, no último grau de ensino da língua, Coménio aconselha a utilização de textos.

Coménio (1996, p. 339) faz referência, ainda, a outros livros que podem ajudar na utilização mais rápida e com maior eficiência cada um dos quatro livros escolares referidos acima. Tratam-se dos denominados livros auxiliares ou livros subsidiários. São eles: o vocabulátio, o dicionário etimológico, o dicionário fraseológico e um prontuário universal.

\section{OS GRAUS DAS INSTITUIÇÕES ESCOLARES E OS TEXTOS ESCOLARES}




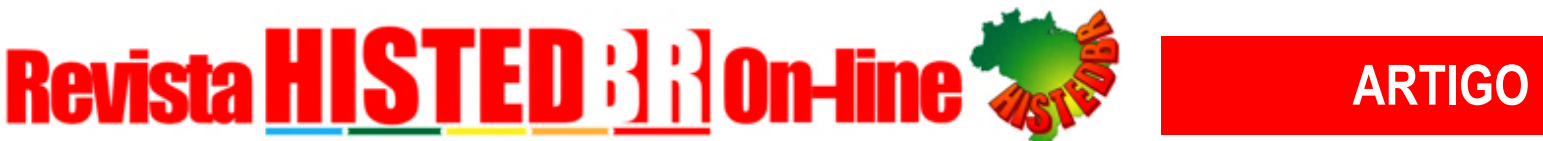

A organização da instrução no âmbito das instituições escolares, conforme Coménio, deve ter como modelo o sistema de aprendizagem dos mestres artesãos. Para promover o ensino das artes, das ciências e das línguas é preciso estabelecer um período determinado para que os alunos possam, neste espaço de tempo, concluir todo o percurso dos seus estudos e, assim, sair das "[...] oficinas de humanidade homens verdadeiramente instruídos, verdadeiramente morigerados e verdadeiramente piedosos." (COMÉNIO, 1996, p. 409).

No entender de Coménio, para se oferecer "educação perfeita do homem todo" eram necessários vinte e quatro anos de estudos, ou seja, desde a infância até a idade viril. Esse período de instrução da juventude se divide em fases, de acordo com a idade e com o nível de aproveitamento dos estudantes. Com este pressuposto, Coménio propôs a organização das instituições escolares em quatro graus, cada um deles constituído de seis anos, de modo que:

I. O regaço materno seja a escola da infância; II. A escola primária (ludus literarius), ou a escola pública de língua vernácula, seja a escola da puerícia; III. A escola de latim ou o ginásio seja a escola da adolescência; IV. A Academia e as viagens sejam a escola da juventude. (COMÉNIO, 1996, p. 410).

Nas diversas escolas devem ser ensinadas as mesmas coisas, porém de maneira diversa. Em outras palavras, significa dizer que todas as coisas ensinadas devem ter a finalidade de tornar a juventude sábia, cristã e virtuosa; devendo, no entanto, conduzir o ensino consoante a idade e o grau de conhecimento adquirido anteriormente, de forma a conduzir a um saber cada vez mais elevado. (COMÉNIO, 1996, p. 411).

É interessante, para o objetivo deste estudo, registrar que, para todos os graus que compõem a organização escolar pensada por Coménio, são recomendados a utilização dos livros de texto (livros didáticos, livros de resumos). Isto pode ser constatado, quando o educador morávio aborda os planos da escola materna, da escola de língua nacional, da escola latina e da Academia.

\section{PLANO DA ESCOLA MATERNA}

A partir de uma analogia com o crescimento das partes componentes de uma árvore, Coménio vai assinalar que as coisas consideradas úteis para a vida do homem precisam ser ensinadas logo na primeira escola, ou seja, na escola materna (escola da infância). Esse grau de instrução, que deveria ser desenvolvido na casa das famílias, estava voltado essencialmente para exercitar os sentidos externos das crianças, de formar a possibilitar a exploração e diferenciação dos objetos pertencentes ao ambiente onde elas viviam.

O pensador morávio demonstra a partir de vinte pontos, o detalhamento dos gérmens e rudimentos de conhecimentos a serem ensinados às crianças pelos pais e amas, tendo em vista um catálogo de matérias que compõem o programa da escola materna, tais como: metafísica, ciências físicas, óptica, astronomia, geografia, cronologia, história, aritmética, 


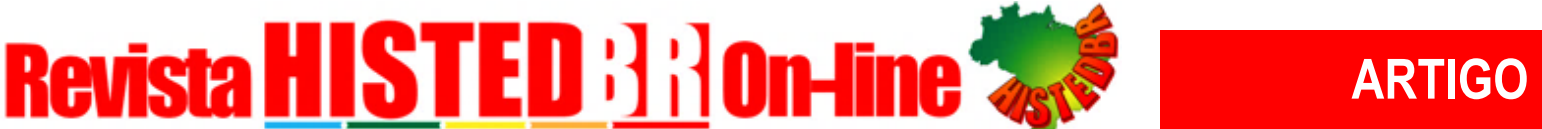

geometria, estática, artes mecânicas, arte dialéctica, gramática infantil, retórica, poesia, música, economia doméstica, política, moral, religião (e piedade).

Para dar consequência ao plano da escola da infância, Coménio afirma ser necessário providenciar dois materiais de grande ajuda para desenvolver, com segurança, a missão de auxiliar as crianças a dar os primeiros passos pelos caminhos da educação.

Um desses materiais - o Livro de conselhos - servia para que os pais e as amas não se esquecessem de seus deveres na educação das crianças pequenas. Esse livro deveria ser compilado com o objetivo de "[...] expor-se, uma por uma, todas as coisas em que é necessário formar a infância, e dizer de que ocasiões deve aproveitar-se para agir, e quais as maneiras e as regras que devem observar-se na fala e no gesto para incutir nas crianças as noções mais elementares." (COMÉNIO, 1996, p. 422).

O outro material indicado por Coménio (1996, p. 422-423) para ser utilizado na escola da infância é o intitulado Livrinho de Imagens. Esse livro, criado para ser utilizado pelas próprias crianças, era composto de figuras e palavras relacionadas com as primeiras noções dos conhecimentos que faziam parte da matéria da escola materna (história, óptica, astronomia, geometria, e outras). Nesse livro, a criança podia pintar desenhos de coisas, de utensílios domésticos, de instrumentos dos artesãos e de pessoas, para então relacionar o significado dos desenhos às palavras inscritas sobre eles, com a finalidade de apreender, por meio dos sentidos, noções básicas do programa didático (como por exemplo, a leitura e a escrita). Na opinião de Coménio, o Livrinho de Imagens tinha três utilidades:

1. ajuda a imprimir as coisas na mente das crianças; 2. atrai os espíritos tenros a procurar em qualquer outro livro coisas para se divertir; 3. faz aprender a ler mais fàcilmente, pois, como as figuras das coisas têm o seu nome escrito por cima, poderá começar-se a ensinar a ler, ensinando a ler as letras desses nomes. (COMÉNIO, 1996, p. 423).

\section{PLANO DA ESCOLA DE LÍNGUA NACIONAL}

Coménio admite a necessidade de toda a juventude, homens e mulheres frequentarem, primeiramente, a escola de língua nacional (vernácula) ${ }^{7}$, para, em seguida, passar aos estudos propostos pela escola latina. Embora, alguns pensadores da época, discordassem dessa ideia, ele, a partir da exposição de uma série de argumentos em prol da educação universal, ponderava que todos os jovens (os ricos e os pobres) deveriam aprender as línguas vernáculas de cada povo, além da língua latina. E, dessa forma, todos poderiam, também, ter acesso à instrução geral capaz de desenvolver todas as faculdades humanas. (COMÉNIO, 1996, p. 425-427).

O plano da escola de língua nacional, segundo o pensador morávio, tinha como meta ensinar a toda juventude, de seis a doze (ou treze) anos de idade, um conjunto de coisas que seriam consideradas úteis para toda a vida (como, por exemplo, ler, escrever, contar, recitar 


\section{Revista HIISTED Biliontine}

ARTIGO

as histórias e as máximas principais da Sagrada Escritura). Caso esse plano fosse colocado em prática de forma eficiente, os adolescentes estariam preparados para continuarem os estudos na escola latina, bem como para desempenharem funções no comércio, na agricultura ou nos ofícios manuais. (COMÉNIO, 1996, p. 429).

A meta desse plano de estudo é alcançada por meio de três estratégias. A primeira, os estudantes da escola de língua nacional, com duração de seis anos, são distribuídos em seis classes, funcionando em lugares separados. A segunda estratégia é destinar livros de texto próprios, contendo todo o programa prescrito para cada classe (relativos à instrução, à moral e à piedade), de maneira que não seja necessário nenhum outro livro. E, finalmente, a terceira estratégia, o uso de um método fácil para apresentar à juventude os livros acerca da língua nacional. (COMÉNIO, 1996, p. 430-434).

O educador morávio se detém a explicar de forma minuciosa como eram os livros de texto (a sua natureza) destinados aos estudantes das classes que compunham a escola de língua nacional. Inicialmente, ele esclarece que cada classe deve ter acesso a apenas um livro com a totalidade das coisas a serem estudadas. Com isso, ao longo dos seis anos que constituem a escola primária, os alunos entrariam em contato com seis livros, um para cada uma das seis classes. Esses livros são diferentes entre si, mais pela forma de abordagem que pela matéria tratada. $\mathrm{O}$ pensador explica essa questão:

Com efeito, todos tratarão de todas as coisas; mas o primeiro apresentará os aspectos mais gerais, mais conhecidos, mais fáceis; o seguinte promoverá a intelecção de aspectos mais especiais, mais desconhecidos e mais difíceis, ou oferecerá um modo novo de considerar as mesmas coisas, para fazer saborear novas delícias aos espíritos. (COMÉNIO, 1996, p. 430).

Os livros de texto a serem usados pelas crianças para aprenderem a língua vernácula, esclarece Coménio (1996, p. 431), tinham que ser adaptados aos "espíritos infantis". Em outras palavras, os livros deviam ser elaborados de forma a apresentar a matéria de modo agradável, lúdico, jocoso. Pois, para que a criança aprenda coisas séries, com mais facilidade e prazer, é preciso saber unir o útil ao agradável.

Com a finalidade de "aliciar" o espírito das crianças e dos jovens para o estudo das línguas, Coménio sugere que os livros para as classes da escola primária fossem ornados com títulos suaves. Os títulos deveriam exprimir de maneira elegante o conteúdo do livro. A este respeito, o educador coloca:

Espero que esses títulos sejam tirados das espécies dos jardins dessa ameníssima propriedade que é a escola. Efectivamente, porque a escola se compara a um jardim, porque é que o livrinho da primeira classe se não há de chamar Canteiro de violetas, o da segunda Roseiral e o da terceira Vergel, etc.? (COMÉNIO, 1996, p. 431). 


\section{Revista HISTED BifilOn-Hine arrico}

\section{PLANO DA ESCOLA DE LÍNGUA LATINA}

A escola de latim ou ginásio, organizada para atender os adolescentes, deveria ser fundada em todas as cidades, com a finalidade de formar a inteligência e o juízo, tendo como base todas as coisas captadas por meio dos sentidos. (COMÉNIO, 1996, p. 410-411).

Ao estabelecer, as metas a serem atingidas, durante o período estipulado para o funcionamento da escola latina, Coménio (1996, p. 437-439) determina o ensino de quatro línguas (nacional, latina, grega e hebraica), com as quais seria possível atingir toda a enciclopédia das Artes. Além das sete Artes liberais (Gramática, Dialética, Retórica, Matemática, Geometria, Música e Astronomia) “tão decantadas”, os alunos, para alcançarem um estágio mais elevado de conhecimento e de cultura, deveriam ser instruídos também em matérias que os preparassem para serem: naturalistas, geógrafos, cronologistas, historiadores, moralistas e teólogos.

Os objetivos propostos para a escola de latim ou ginásio seriam alcançados, dividindo o conteúdo da instrução em seis classes ao longo de seis anos. As classes organizadas da mais baixa para a mais elevada ${ }^{8}$ receberiam as seguintes denominações: I) Gramática; II) Física; III) Matemática; IV) Ética; V) Dialética, e VI) Retórica. (COMÉNIO, 1996, p. 439).

O educador morávio reconhecendo a importância da história como parte da instrução dos adolescentes, afirma que os conhecimentos históricos deveriam ser distribuídos nas seis classes que constituem a escola latina. Com o propósito de tornar mais prudente e mais agradável aos alunos a transmissão dos conteúdos de história, Coménio sugere a compilação de um "livrinho especial" para cada classe desse nível de instrução, contendo "um certo gênero de factos históricos", de acordo com o programa distribuído ao longo das seis classes: "I. Compêndio de história sagrada; II. História das ciências naturais. III. História das artes e das invenções. IV. História da moral [...]. V. História dos ritos [...]. VI. História Universal [...]". (COMÉNIO, 1996, p. 445).

Para entender melhor a concepção de textos escolares nesse momento histórico é significativo registrar que, para Coménio (1996, p. 445), todo o conteúdo de história a ser ensinado ao longo dos seis anos deveria ser "[...] exposto resumidamente, tratando apenas das coisas necessárias e omitindo as que não têm importância.”

\section{A ACADEMIA}

A Academia, que deveria existir em todos os reinos e até nas províncias mais importantes, constituía o último grau das instituições escolares, sendo destinada à formação da juventude. Embora tendo declarado que o seu método de ensino não se estende até a Academia (Universidade), Coménio tece algumas considerações que permitem entender a sua proposta acerca da organização do trabalho didático e dos instrumentos didáticos a serem utilizados nesta etapa da educação dos jovens. 


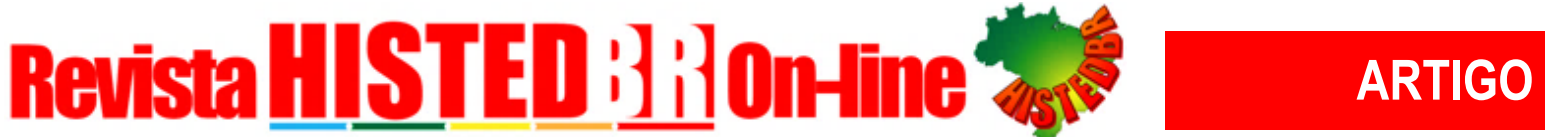

Segundo o autor (1996, p. 448-449), os trabalhos na Academia fluiriam com maior êxito se para lá fossem encaminhados somente os "[...] engenhos mais selectos, a flor dos homens; os outros, enviar-se-ão para a charrua, para as profissões manuais, para o comércio, para que, aliás, nasceram [...]", bem como se na Universidade o jovem estudasse um determinado ramo do conhecimento, para o qual ele tem maior aptidão (relacionado à sua "inclinação natural") e lá fosse estimulado os "engenhos heróicos" que acumularam vastos e elevados conhecimentos.

Coménio, ao explicar as finalidades dos estudos na Academia ${ }^{9}$, faz colocações que revelam com clareza a natureza da organização do trabalho didático neste grau da instituição escolar daquela época, nos primórdios da sociedade moderna. O autor indica uma série de procedimentos que deveriam ser seguidos, para que o trabalho na Academia prosseguisse mais facilmente e de maneira mais eficiente, de forma contribuir para a formação dos homens que iriam ocupar os altos cargos públicos na sociedade da época. Dentre esses procedimentos estão os seguintes: a) os colóquios públicos (exercícios coletivos) baseados na leitura prévia de livros de grandes autores; b) as preleções do professor (lições) e os questionamentos dos alunos; c) as disputas (exames públicos por meio de perguntas e respostas) para verificar o progresso teórico e prático dos alunos (e conferir o título de Doutor ou de Mestre); d) as viagens para ampliar os conhecimentos; e) a criação de uma "sociedade didáctica" para descobrir os fundamentos das ciências, para depurar e difundir a sabedoria, bem como buscar despertar o interesse do homem para as novas invenções. (COMÉNIO, 1996, p. 451-454).

Ao tratar especificamente dos instrumentos didáticos a que o professor deveria recorrer para ensinar na Academia, Coménio, sugere que se peça às pessoas doutas, aos filósofos, aos teólogos, aos médicos que façam resumos (para ser editados) das "coisas substanciais" $"$, das obras de autores como Cícero, Lívio, Platão, Aristóteles, Plutarco, Santo Agostinho para serem lidos pela juventude, de forma tornar o estudo menos penoso. A produção de resumos das obras clássicas teria, na opinião do educador morávio, grande utilidade:

Em primeiro lugar, para aqueles que não têm tempo para ler obras extensas, para que ao menos adquirissem um conhecimento geral desses autores. Em segundo lugar, para aqueles que (segundo o conselho de Sêneca) desejassem familiarizar-se apenas com um autor (pois nem todas as coisas convêm igualmente a todos) pudessem escolher mais fàcilmente e mais judiciosamente, quando, tendo saboreado vários autores, tivessem sentido que este ou aquele está mais em relação com os seus gostos. Em terceiro lugar, esses resumos prepararão muito bem para uma leitura mais frutuosa aqueles que deverão estudar as obras completas, da mesma maneira que, para um viajante, o facto de ter conhecido no mapa a corografia de determinada região, o ajuda a observar com mais facilidade, com mais segurança e com maior prazer todas as particularidades que, a seguir, lhe caem sob os olhos. Finalmente, esses breviários servirão a todos, para fazer mais ràpidamente as revisões necessárias dos autores e para deles extrair a substância que se fixa no espírito e se transforma em alimento vital. (COMÉNIO, 1996, p. 450). 


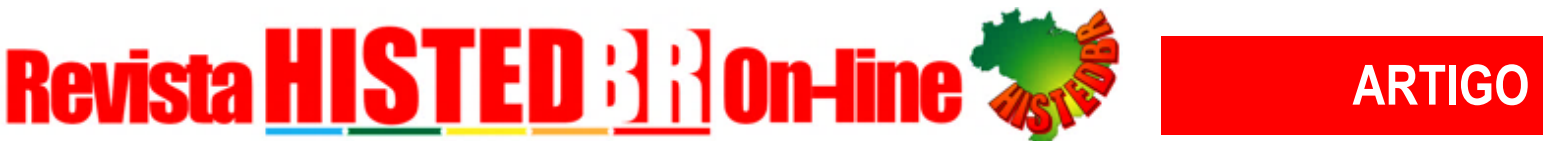

É importante esclarecer que, embora, Coménio (1996, p. 448) sugerisse a produção de resumos das obras clássicas para uso na Academia, ele afirma também que, nesse grau de educação, dever-se-ia estudar todo o gênero de autores. Para isso, era necessário uma "Biblioteca selecta" com um acervo de vários autores para ser utilizada de forma comum por todos os estudantes. Além, de ser necessário contar com professores "eruditos e ardorosos" para comunicar o conhecimento à juventude.

\section{A ORGANIZAÇÃO UNIVERSAL E PERFEITA DAS ESCOLAS: O PAPEL CENTRAL DOS TEXTOS ESCOLARES}

O educador morávio, demonstrando perspicácia em apreender as mudanças sociais do seu tempo, vai, também, tomar como protótipo do seu método de educar, além da natureza, as "coisas artificiais": a arte. Para explicar como a escola e o professor deveriam proceder para conduzir, com sucesso infalível, o progresso intelectual dos estudantes, ele recorre a frequentes analogias, não só com os seres da natureza, mas também com os objetos já transformados pela ação humana. A arte de ensinar deve seguir as pegadas da natureza e das artes em geral. O relógio e a arte tipográfica são exemplos expressivos tomados por Coménio para explicar a organização do trabalho escolar, a partir das transformações que vinham se processando no interior da sociedade, no século XVII.

Para fazer um resumo dos seus conselhos e votos acerca da organização do trabalho didático, Coménio recorre a uma analogia entre a arte tipográfica e a arte de ensinar, denominada por ele de "Didacografia".

$\mathrm{Na}$ Didacografia, o texto escolar e os outros instrumentos de trabalho do professor são comparados aos tipos metálicos (caracteres) da imprensa. Dessa forma, os livros didácticos, como um tipógrafo perfeito devem, conforme Coménio (1996, p. 459-460): a) ser preparados em abundância para permitir a execução do novo método; b) conter toda a cultura necessária à formação plena dos espíritos; c) distribuir os conhecimentos de forma distinta, conforme as tarefas de um ano, de um mês, de um dia e de uma hora; d) ser adequados às necessidades de cada classe, evitando distração e confusão.

Ainda, valendo-se do exemplo do tipógrafo, Coménio esclarece que é preciso a elaboração de livros-roteiros a serem colocados nas mãos dos educadores da juventude. Os livros-roteiros serviam para orientar os professores no que "[...] hão-de fazer, em que lugar e de que modo, para que se não caia em erro." (COMÉNIO, 1996, p. 460). Assim, verificase que, o educador morávio propõe dois gêneros de livros didácticos: “[...] verdadeiros livros de texto para os alunos, e livros-roteiros (informatorii) para os professores, para que aprendam a servir-se bem daqueles" (COMÉNIO, 1996, p. 460).

O professor, na analogia entre a didática e a arte tipográfica, é a tinta. Ou seja, é a voz do professor que dará vida aos "caracteres das ciências" impressos nos livros de texto e 


\section{RevistaHISTED Billontine}

que, por sua vez, deverão ser registrados nas mentes dos estudantes com pouca fadiga e facilmente.

[...] assim também as coisas que os mudos professores das crianças, os livros de texto, colocam diante delas, são realmente mudas, obscuras e imperfeitas, mas, quando aos livros se junta a voz do professor (que explica tudo racionalmente, segundo a capacidade dos alunos, e tudo ensina a pôr em prática), tornam-se cheios de vida, imprimem-se profundamente nos seus espíritos, e assim, finalmente, os alunos entendem verdadeiramente aquilo que aprendem. (COMÉNIO, 1996, p. 460-461).

O professor, mesmo não sendo dotado de muitas habilidades como os preceptores da idade média, na opinião do pensador morávio poderia infundir o conhecimento no espírito da juventude, desde que fossem produzidos e colocados em suas mãos os instrumentos necessários, como por exemplo, os livros didácticos. Lembrando que o organista executa uma sinfonia usando uma partitura, Coménio (1996, p. 457), pergunta: o professor não poderia educar a todos se o que e como ele deve ensinar estivesse escrito seguindo o modelo das partituras?

Ao tratar, de maneira pormenorizada, sobre o método didáctico e a questão da impressão dos livros de texto, é pertinente acrescentar que o pensador não se esqueceu de referir-se à composição gráfica dos livros mais "elegantemente" a serem produzidos através da tipografia. Ele explica que esses livros deveriam ter "[...] os capítulos, as colunas e os

parágrafos claramente distintos, com certos espaços vazios (requeridos, quer pela necessidade, quer por uma melhor visão), tanto marginais como interlineares." (COMÉNIO, 1996, p. 463).

\section{OS REQUISITOS NECESSÁRIOS PARA COLOCAR EM PRÁTICA O MÉTODO COMENIANO: OS TEXTOS ESCOLARES E O BARATEAMENTO DO ENSINO}

Coménio, no final da Didáctica magna, realiza uma reflexão a respeito das condições das escolas nos reinos e nas repúblicas cristãs. Ele pondera que apesar da indignação e das lamentações de muitos pensadores, há mais de um século, nenhum remédio tenha sido aplicado com êxito para corrigir os "costumes bárbaros" dos colégios e das academias. As instituições escolares, não sofreram mudanças, mesmo as iniciativas particulares não foram levadas adiante devido ao descrédito dos ignorantes, à inveja dos malévolos e à falta de auxílio, afirma o educador morávio. (COMÉNIO, 1996, p. 467-468).

Diante do quadro da educação, no século XVII, Coménio consciente dos condicionantes econômicos impostos pela organização da sociedade do seu tempo, aponta alguns impedimentos para que o seu projeto de reforma e de expansão das escolas universais se tornasse uma realidade. (ALVES, 2001, p. 85). A falta de remuneração adequada e de professores competentes, que pudessem colocar em prática o novo método de ensinar tudo 


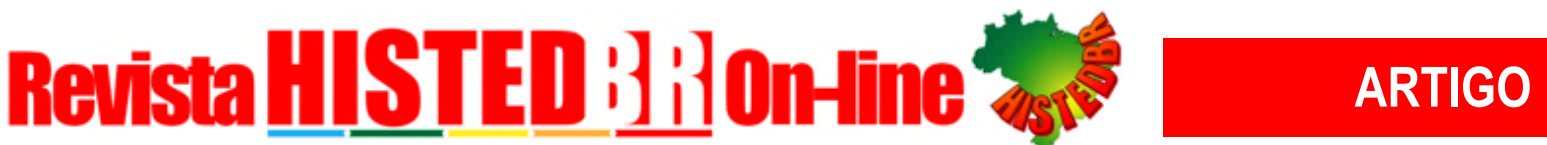

a todos, bem como a inexistência de subsídios para financiar os estudos dos filhos dos pobres e a presença dos "pseudo-sábios" que relutam contra os novos métodos, são empecilhos, segundo o educador morávio (COMÉNIO, 1996, p. 468-469), para a concretização do seu plano educacional. No entanto, ele acredita que há "remédios" para essas dificuldades.

Para se colocar em funcionamento a prodigiosa "máquina" de ensinar a todos os habitantes dos reinos, cidades e povoados, uma só coisa era imprescindível para Coménio: providenciar uma "provisão suficiente de livros pan-metódicos". Pois, todo o processo educativo poderia ser comprometido caso faltassem os "livros didácticos", considerado o instrumento central do trabalho do professor. O educador enfatiza que:

Efectivamente, da mesma maneira que, fornecendo o material tipográfico, é fácil encontrar quem o possa, saiba e queira utilizar, e quem ofereça qualquer soma para imprimir bons e úteis livros, e quem compre esses livros, de preço acessível e de grande utilidade, assim também seria fácil, uma vez preparados os meios necessários para a pan-didáctica, encontrar os fautores, os promotores e os directores de que ela precisa. (COMÉNIO, 1996, p. 469).

A realização do grandioso empreendimento educacional proposto por Coménio pressupunha a economia de tempo e de dinheiro, marca da nova ordem social capitalista (período das manufaturas) que surgia dos escombros do período feudal. Era necessário baratear a educação que se almejava oferecer a todos os homens e mulheres (universalização da educação). Então, para colocar em funcionamento o seu projeto, ele propôs o uso dos textos escolares como uma solução para os custos do ensino. Para educar de forma sólida, rápida e eficiente era suficiente que o professor recorresse a esse instrumento, que objetivou o trabalho didático e, como consequência, simplificou as atividades do professor manufatureiro. O professor "sábio", que dominava todos os campos do conhecimento, exaltado pelos humanistas, como Erasmo, é superado pelo tempo. A nova organização da sociedade capitalista passa a exigir um novo instrumento para o trabalho didático. (ALVES, 2001).

Gilberto Luiz Alves, em seus estudos sobre a produção da escola pública contemporânea, analisa no leito da história, o surgimento e a função dessa nova tecnologia educacional: o manual didático.

O manual didático surgiu com a pretensão de consubstanciar uma síntese dos conhecimentos humanos sob uma forma mais adequada ao desenvolvimento e à assimilação da criança e do jovem. Especializou-se, também, em função dos níveis de escolarização e das áreas de conhecimento, multiplicando-se da mesma forma que os instrumentos de trabalho, dentro da oficina, que, por força da divisão do trabalho, ganharam as configurações mais adequadas às operações que realizavam. Desde então, o manual didático passou a servir em tempo integral ao aluno e ao professor. Foram criadas, mesmo, modalidades especializadas de textos para aquele e para este, mas, rigorosamente, concebidas como elementos complementares. De imediato, importa reconhecer que o manual didático, 


\section{RevistaHIISTED Bition Hine ARTico}

pela sua auto-suficiência enquanto instrumento organizador do trabalho de ensino, dispensou da escola o livro clássico. (ALVES, 2001, p. 86-87).

Como consequência da disseminação do manual didático e pela sua "autosuficiência" enquanto instrumento que orienta a organização do trabalho do professor, Alves (2001) deixa claro que, os livros clássicos perderam espaço, ou mesmo desapareceram das bibliotecas escolares e das salas de aula na sociedade contemporânea.

\section{CONSIDERAÇÕES FINAIS}

Com o presente texto, procurou-se realizar a exposição do estudo desenvolvido a respeito da concepção e da função do texto escolar na obra Didáctica magna, escrita por Coménio, em meados do século XVII. A releitura da obra permitiu levantar alguns elementos relacionados à organização do trabalho didático, que podem contribuir com as pesquisas empreendidas no campo da história da educação.

Coménio, um genuíno representante do movimento da Reforma Protestante, deixa explícita sua posição a respeito dos materiais didáticos que o professor deveria lançar mão para ensinar todos os homens e todas as mulheres a ler e a escrever e, em decorrência, ter acesso aos ensinamentos da Sagrada Escritura. O manual didático é o principal instrumento proposto pelo educador morávio para o trabalho do professor. Ao expor suas ideias sobre o melhor método a ser seguido pelo mestre, para executar com segurança a atividade educativa, Coménio recomendou, reiteradamente, na sua Didáctica magna o uso do livro texto pelo professor e pelos alunos, em todos os graus das instituições escolares do seu tempo.

Com a finalidade de ensinar a todos com economia de tempo e fadiga Coménio aconselha o uso de livros de texto próprio para cada uma das classes que compunham as etapas de educação, a fim de se evitar confusão e dificuldades aos estudantes. Os livros deveriam ser produzidos conforme as leis da facilidade, da solidez e da brevidade. Assim, os conteúdos precisam ser apresentados de modo familiar, para que os alunos possam compreendê-los, mesmo sem a presença do professor. Aqui, talvez esteja o ponto mais significativo da proposta comeniana. Todo o espírito da modernidade parece contido nesse único princípio. As leis que balizam o pensamento de Coménio são as mesmas que regulam o funcionamento da sociedade capitalista. Os livros de texto, mais tarde qualificados como "didáticos", atendem, perfeitamente, as motivações que emanam dessas leis. Dão ao trabalho do ensino a brevidade que o tempo recomendava. Organizam o ensino escolar numa base completamente nova, negando a base dada pela sociedade medieval, porque quebra $\mathrm{o}$ monopólio da Igreja Católica sobre a educação, ao subtrair do professor o controle na atividade do ensino.

A proposta anunciada por Coménio no século XVII, na Didáctica magna, da utilização dos manuais didáticos como ferramenta fundamental para promover a educação 


\section{RevistaHISTED HilOnHine A ARTIGo}

de crianças e jovens, ganhará novo vigor em meados do século XIX, no interior do movimento pedagógico, denominado - Escola Nova. A base material capitalista, já plenamente desenvolvida, estabelecerá as condições necessárias para a expansão da escola pública que agora abrirá suas portas, não apenas para os filhos da burguesia como também para os filhos dos trabalhadores.

Segundo Alves (2001), a escola pública que se universalizou a partir do último terço do século XIX, incluindo assim os filhos dos trabalhadores, sofreu mudanças na natureza do conhecimento que era ofertado. Em outros termos, os conteúdos escolares ministrados pelo professor sofreram um processo "progressivo de aviltamento". A fonte dos currículos escolares passa a ser, prioritariamente, o manual didático, aquele instrumento idealizado por Coménio, dois séculos atrás.

\section{REFERÊNCIAS}

ALVES, G. L. A produção da escola pública contemporânea. Campinas, SP: Autores Associados; Campo Grande, MS: Ed. UFMS, 2001.

ALVES, G. L. O trabalho didático na escola moderna: formas históricas. Campinas, SP: Autores Associados, 2005.

ALVES, G. L. Textos escolares do ensino secundário no Brasil: da época jesuítica aos nossos dias. In: ALVES, G. L. (org.). Textos escolares no Brasil: clássicos, compêndios e manuais didáticos. Campinas, SP: Autores Associados, 2015, p. 5-60.

ALVES, G. L. Textos escolares no Brasil. In: JORNADA DO HISTEDBR/MS "ESTUDOS SOBRE ORGANIZAÇÃO DO TRABALHO DIDÁTICO”, 1., 2011, Campo Grande. Anais [...]. Campo Grande, UNIDERP: Anhanguera, 2011. p. 1-32.

BRITO, S. H. A. A produção de manuais didáticos e o ensino de sociologia na escola média em dois momentos históricos (1935-1989). Revista HISTEDBR On-line, Campinas, SP, num. especial, p. 58-75, maio 2010. Disponível em: http://www.histedbr.fae.unicamp.br. Acesso em: 24 set. 2010.

CENTENO, C. V. O conhecimento histórico vulgarizado: a "ditadura" do manual didático. Revista HISTEDBR On-line, Campinas, SP, n. 33, p. 169-178, mar. 2009. Disponível em: http://www.histedbr.fae.unicamp.br. Acesso em: 7 ago. 2010.

COMÉNIO, J. A. Didáctica magna: tratado da arte universal de ensinar tudo a todos. Lisboa: Fundação Calouste Gulbenkian, 1996.

GOMES, J. F. Introdução. In: COMÉNIO, J. A. Didáctica magna: tratado da arte universal de ensinar tudo a todos. Lisboa: Fundação Calouste Gulbenkian, 1996. p. 5-41.

MARX, K. O capital. Rio de Janeiro: Bertrand Brasil, 1989. Livro 1. v. I. 


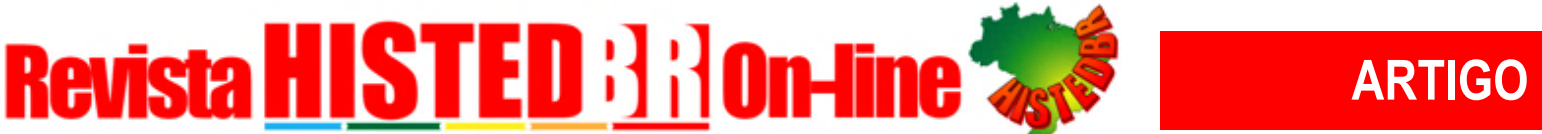

SOUZA, A. A. A. de. Manuais didáticos: formas históricas e alternativas de superação. In: BRITO, S. H. A. et al. (org.). A organização do trabalho didático na história da educação. Campinas, SP: Autores Associados: HISTEDBR, 2010. p. 121-145.

VALDEMARIN, V. T. Os sentidos e a experiência: professores, alunos e métodos de ensino. In: SAVIANI, D. et al. O legado educacional do século XX no Brasil. Campinas, SP: Autores Associados, 2006. p. 163-203.

\section{AUTORIA:}

* Doutorado em Educação pela Universidade Federal de Mato Grosso do Sul (UFMS). Docente sênior do Programa de Pós-Graduação Strictu Sensu - Mestrado Profissional em Educação da Universidade Estadual de Mato Grosso do Sul (UEMS). Contato: iara2ufms @ gmail.com.

** Graduação em Letras - Português e Espanhol pelo Centro Universitário de Jales (UNIJALES). Professora Formadora de Linguagens na Coordenadoria Regional de Educação Metropolitana da Secretaria de Estado de Educação de Mato Grosso do Sul (SED-MS). Contato: prof.vanessarubinho@gmail.com.

*** Graduação em Pedagogia pela Universidade Católica Dom Bosco (UCDB). Diretora Adjunta da Escola Municipal Prof. Licurgo de Oliveira Bastos, Campo Grande, MS. Contato: patriciafscardoso@gmail.com

\section{COMO CITAR ABNT:}

SILVA, I. A. da; RUBINHO, V. da S.; CARDOSO, P. F. da S. Os textos escolares na Didáctica Magna de Coménio. Revista HISTEDBR On-line, Campinas, SP, v. 21, p. 1-21, 2021. DOI: 10.20396/rho.v21i00.8660735. Disponível em: https://periodicos.sbu.unicamp.br/ojs/index.php/histedbr/article/view/8660735. Acesso em: 02 ago. 2021.

\section{Notas}

${ }^{1}$ Gilberto Luiz Alves esclarece o significado histórico da expressão "manual didático". Conforme o autor $(2015$, p. 9), no plano teórico, "[...] a produção do manual didático, nas origens da escola moderna, originou o texto escolar no sentido estrito. Ela representou o surgimento de um novo tipo de instrumento do trabalho docente, agora especializado, pois sua razão de ser vinculava-se especificamente à simplificação e à divisão do trabalho didático. Seu uso na escola realizou relevante incursão a fim de impor o domínio do instrumento de trabalho sobre o professor. Logo, a singularidade da denominação manual didático implica, necessariamente, todos esses aspectos reveladores de sua historicidade. O domínio absoluto do manual didático na relação educativa escolar foi a tendência claramente apontada por Comenius."

${ }^{2}$ A categoria de análise organização do trabalho didático é considerada fundamental para explicar a função do manual didático. Para Alves (2005, p. 10-11), a organização do trabalho didático envolve três aspectos: "a) ela é, sempre, uma relação educativa que coloca, frente a frente, uma forma histórica de educador, de um lado, e uma forma histórica de educando (s), de outro; b) realiza-se uma mediação de recursos didáticos, envolvendo os procedimentos técnico-pedagógicos do educador, as tecnologias educacionais pertinentes e os conteúdos programados para servir ao processo de transmissão do conhecimento; c) e implica um espaço físico com características peculiares, onde ocorre." 


\section{RevistaHISTED Biliontine}

${ }^{3}$ Dentre esses pesquisadores pode-se destacar: Gilberto Luiz Alves, Carla Villamaina Centeno, Samira Saad Pulchério Lancilotti, Silvia Helena Andrade de Brito, Ana Aparecida Arguelho de Souza.

${ }^{4}$ Vera Teresa Valdemarin (2006, p. 166), em seus estudos sobre o método de ensino intuitivo, também ressalta que "[...] a Didactica magna, publicada por J. A. Comênio em 1670, é a obra educacional que apresenta as diretrizes gerais para o funcionamento da instituição escolar moderna (organizada em séries, destinada a todos, com professores e materiais próprios). Nessa obra pioneira, a necessidade da transmissão do conhecimento é proposta para todos os indivíduos, devendo ficar a cargo de especialistas, em consonância com a divisão social do trabalho então em curso na sociedade."

${ }^{5}$ É interessante registrar, que o próprio Coménio (1996, p. 48-49), ao propor na "Saudação aos leitores" uma "[...] nova arte de ensinar e aprender [...]" que imprimisse outro formato às escolas que se "[...] curvavam ao peso de fadigas e de caprichos, de hesitações e de ilusões, de erros e de faltas [...]", coloca que, já há algum tempo, outros pensadores vinham investigando e propondo em seus livros uma nova didática para ensinar. Dentre outros pensadores, Coménio cita Ratke, Lubin, Bodin, Vogel, João Valentim Andrea e Jean-Cécile Frey. Isto indica que o tempo era de buscar novos caminhos para a escola que surgia do esfacelamento do antigo regime feudal.

${ }^{6}$ Joaquim Ferreira Gomes (1996, p. 33-41), na Introdução da Didáctica magna, esclarece que nos trinta e três capítulos que compõem esta obra podem ser distinguidas quatro partes: a) primeira parte (capítulo I-VI) - fundamentos teológicos e filosóficos da educação; b) segunda parte (capítulo VII-XIX) - dedicada aos princípios da didáctica geral; c) terceira parte (capítulo XX-XXVI) consagrada à didáctica especial; d) quarta parte (capítulo XXVII-XXXI) - apresenta um esboço de um plano orgânico de estudos. Ainda, segundo Gomes (1996), o capítulo XXXII apresenta um "resumo dos votos e dos conselhos" expostos ao longo da Didáctica magna. No último capítulo (XXXIII), Coménio (1996, p. 41) faz um "[...] vibrante apelo aos pais, aos formadores da juventude, às pessoas instruídas, aos teólogos, aos governantes e a Deus, para que ajudem a realizar os projetos expostos."

${ }^{7}$ Nas escolas públicas de língua vernácula (escolas primárias), as quais deveriam existir em todas as comunas, vilas e aldeias, segundo Coménio (1996, p. 411), era preciso criar condições para "[...] exercitar-se os sentidos internos, a imaginação e a memória, juntamente com os seus órgãos executores, as mãos e a língua, lendo, escrevendo, pintando, cantando, contando, medindo, pesando, imprimindo várias coisas na memória, etc."

${ }^{8}$ Coménio (1996, p. 439-445) procura expor os seus argumentos para justificar a sequência das matérias apresentadas para cada uma das seis classes, tendo como princípio que é necessário, primeiro, adquirir conhecimentos das coisas captadas pelos sentidos, para então, fazer julgamentos racionais delas. Por isso, as ciências naturais devem ser ensinadas antes das ciências morais. No interior das argumentações, o autor vai esclarecendo o que e como se deve abordar tais matérias que compõem o plano da escola latina.

9 As finalidades da Academia, segundo Coménio (1996, p. 447) são as seguintes: 1) proporcionar estudos verdadeiramente universais, que propicie o acesso a todo o conhecimento das letras e das ciências humanas; 2) adotar métodos fáceis e seguros para incutir nos jovens uma "erudição sólida"; 3) preparar jovens dignos e idôneos para ocupar os cargos públicos.

${ }^{10}$ Coménio (1996, p. 450), ao sugerir a produção de resumos dos textos clássicos, esclarece que não está propondo que se faça apenas "[...] extractos de sentenças e florilégios [...]", como algumas pessoas faziam naquele tempo. Ele recomenda que se realize o resumo da obra inteira para extrair as ideias principais. 